\title{
Healthy lifestyle habits among Greek university students: differences by sex and faculty of study \\ I. Tirodimos, ${ }^{1}$ I. Georgouvia, ${ }^{1}$ T-N. Savvala, ${ }^{1}$ E. Karanika ${ }^{1}$ and D. Noukari ${ }^{1}$
}

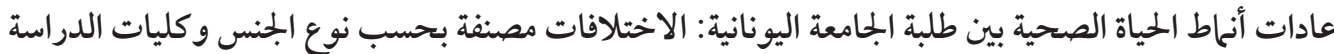

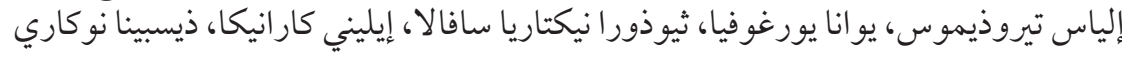

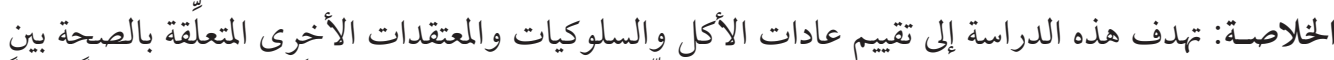



ABSTRACT The objective of this survey was to assess the eating habits and some health-related behaviours and beliefs of students at Aristotle University of Thessaloniki, Greece. Data from a selfcompleted anonymous questionnaire to 300 students were analysed with emphasis on differences by sex and faculty of study. Female students, although they exercised less than men, had higher scores for healthy eating, had a lower rate of overweight/obesity and a lower rate of alcohol consumption. Fewer medical students reported drinking alcohol and smoking than other students, but there was no difference concerning their eating habits.

Modes de vie sains chez les étudiants grecs : différences selon le sexe et la faculté fréquentée RÉSUMÉ L'objectif de cette étude était de faire le point sur les habitudes alimentaires et sur certains comportements et croyances en matière de santé des étudiants de l'université Aristote de ThessaIonique (Grèce). Les données provenant d'un auto-questionnaire anonyme distribué à 300 étudiants ont été analysées, l'accent étant mis sur les différences selon le sexe et la faculté fréquentée. Les étudiantes faisaient moins d'exercice que les étudiants, mais elles obtenaient de meilleurs scores en ce qui concerne l'alimentation saine et des taux inférieurs de surpoids/obésité et de consommation d'alcool. D'après leurs réponses, les étudiants en médecine buvaient moins d'alcool et fumaient moins que les autres étudiants, mais leurs habitudes alimentaires n'étaient pas différentes. 


\section{Introduction}

A significant amount of the mortality and morbidity experienced worldwide today is preventable [1]. The major determinants of health are socioeconomic factors, lifestyle factors and the physical environment [2]. Lifestyle-related risk factors that were acknowledged in The European health report of the World Health Organization (WHO) included unhealthy nutrition, physical inactivity, tobacco use and the use of alcohol and illicit drugs [2].

Health-related behaviour in early life influences later risks for lifestyle-related disorders. It is therefore important to investigate health behaviours among young people. University students represent a major segment of the young adult population. It makes sense to focus on them, for example in studies of the association between beliefs and practices for a healthy lifestyle, in order to design effective health promotion activities targeting this group [3].

Regarding healthy nutrition, the traditional Greek diet, a variant of the Mediterranean diet, has attracted the interest of scientists for many years as a healthpromoting nutritional model [4]. It is rich in legumes, fish, vegetables, fruits, cereals and olive oil, whereas meat is eaten rarely. However, in recent years in Greece the traditional Greek diet is mainly followed by the elderly population [5]. The the younger population, on the other hand, has been adopting a more "westernized" diet combined with a less physically active way of life.

Although universities and colleges are potentially important targets for the promotion of healthy lifestyles of the adult population, only a few studies have been conducted in Greece examining the dietary and health habits of university students, mainly at the University of Crete in south- ern Greece [6-8]. These studies revealed not only that university students' regular diet contained excessive quantities of saturated fat, cholesterol and sodium, but also that the prevalence of smoking among students was one of the highest reported in the literature.

Our study focused on the nutritional and health habits of university students in Thessaloniki, the second largest city in Greece. Aristotle University of Thessaloniki is one of the largest universities in the Balkan peninsula in terms of student population. To our knowledge, this is the first study in this large university in northern Greece that aimed to measure students' knowledge of nutrition as well as their food and health habits. A particular emphasis was placed on studying differences by sex and faculty of study.

\section{Methods}

The survey was conducted between September 2004 and March 2005. It was carried out within the training framework of the hygiene class, which is presented in the 3rd year of the medical course in Aristotle University Medical School. A sample of all medical students registered in the 3rd year of their studies was asked to complete a self-administered questionnaire. The study also included a sample of 3rd-year students from the faculties of physical sciences, engineering, law and languages which adequately represents the range of subjects studied at the university. Both samples represented adequately the total population of students in the academic year. A total of 345 questionnaires were distributed and 300 were returned completed (response rate $87 \%$ ). The mean age was 21.5 years for both sexes.

Questionnaires were administered to students during class time over 2 semesters.

المجلة الصحية لشرق المتوسط، منظمة الصحة العالمية، المجلد الخامس عشر، العدد ب، 9 +. 
We assured students that their participation was voluntary and asked them to submit their responses anonymously. The questionnaire was designed by the authors to cover areas that are important for studying health and health habits. The validity of the questionnaire was established by basing it on literature reviews of issues related to healthy diet, health habits and motivation for a healthy lifestyle. For example, the 1 -week food frequency questionnaire that was used was based on that reported by Stefanik and Trulson, adapted to the Greek diet [9].

The questionnaire was tested in a pilot study on 30 medical students. It covered the following areas:

- Sociodemographic variables. These included: sex, age, height, weight, father overweight/obese, mother overweight/ obese, student residence (living alone or with parents), faculty attending ( 8 questions). Data on weight and height were used to calculate body mass index (BMI) $\left(\mathrm{kg} / \mathrm{m}^{2}\right)$ and to classify students into overweight/obese or normal weight categories [10].

- Students' awareness and knowledge of nutrition. This was measured by separate questions concerning: the energy content of foods (fats, sugars, proteins); the role of fats; the sources of vitamins and minerals; the components of the Mediterranean diet; the proper percentage content of fats/sugars/proteins in the daily nutrition (5 questions). A percentage score of 0-100 was constructed by summing the number of correct answers. "Medium" knowledge was classified as score 45-60, "good" knowledge was score $>60->75$.

- Students' nutritional habits. Students completed a 3-day diet diary in which they described and wrote down all items of food and drink consumed for 3 consecutive days including 1 weekend day. In addition, a 1-week food frequency questionnaire was completed by each student. The questionnaire covered the previous week and included 40 foods that are the most common in the Greek diet. A score from 0 to 100 was constructed. Eating habits that were judged to be "correct" in terms of healthy nutritional behaviours were: avoiding fat and cholesterol-rich foods, and an effort to eat fruit and fibres.

- Questions related to health habits (physical activity, cigarette smoking and alcohol use). The measure of physical activity was the self-reported number of hours of exercise per week. Regular exercise was defined as exercising $>2$ hours/week. Respondents were asked about the frequency of their weekly consumption of alcoholic beverages during the previous 3 months (units/week). Smokers were classified as those who reported smoking more than 1 cigarette per day for at least 3 consecutive months.

The statistical software package SPSS, version 12.0, was used for the analysis of data. Parametric variables were analysed using the Student $t$-test. The chi-squared test was used for non-parametric variables. $P$-value $<0.05$ was considered statistically significant.

\begin{tabular}{|c|c|c|c|}
\hline \multirow{2}{*}{ Sex } & \multicolumn{3}{|c|}{ No of students } \\
\hline & $\begin{array}{c}\text { Medical } \\
\text { faculty }\end{array}$ & $\begin{array}{c}\text { Ot studer } \\
\text { Other } \\
\text { faculties }\end{array}$ & Total \\
\hline Male & 62 & 79 & 141 \\
\hline Female & 74 & 85 & 159 \\
\hline Total & 136 & 164 & 300 \\
\hline
\end{tabular}




\section{Results}

Table 1 shows the number of students participating in the survey according to sex and faculty of study.

The first hypothesis predicted that women would be characterized by better knowledge and making a greater conscious effort to achieve healthy nutrition, a higher intake of a low-fat diet and a lower frequency of alcohol consumption and smoking. Table 2 shows the students' nutritional and health habits according to sex. The overall mean score for knowledge of healthy foods was judged as medium $(56.8 \%$ for men and $57.9 \%$ for women) and so was the mean score for nutritional habits $(61.8 \%$ for men and $66.7 \%$ for women). Although the female students had significantly higher scores on healthy nutritional habits than the male students $(P<0.003)$ there was no statistically significant association between students' sex and their knowledge about healthy food $(P=0.627)$.

A total of $17.1 \%$ of the students were overweight or obese (BMI $>25 \mathrm{~kg} / \mathrm{m}^{2}$ ), of whom $58.8 \%$ were male and $41.2 \%$ female. Men used alcohol more than women; the overall mean alcohol intake was 4.01 units/week for the male students and 2.46 units/week for the female students $(P<$
0.002). Only a few individuals reported consuming excessive amounts of alcohol on a weekly basis ( $>100 \mathrm{~g}$ for men and $>60 \mathrm{~g}$ for women.). More of the male students exercised regularly ( $>2 \mathrm{~h} /$ week) than did females $(P<0.0001)$, but there was no significant difference in smoking habits among the female and male students $(P<0.615)$.

The second hypothesis predicted that medical students would report better knowledge and have better health behaviours than students from other disciplines and faculties. Table 3 shows the relationship between students' faculty of study and nutritional and health habits. The medical school students had significantly better knowledge of healthy food than the other, non-medical students (mean score $63.1 \%$ versus $52.6 \% ; P<0.0001$ ), but there was no association between nutritional habits and faculty of study. However, significantly fewer of the medical students smoked than the other students; $35.2 \%$ of those smoking were medical students whereas $64.8 \%$ were students of other faculties $(P=0.02)$. The mean amount of alcohol consumed was 2.22 units/week for medical students and 3.98 units/week for other, non-medical students $(P<0.0001)$.

\begin{tabular}{|c|c|c|c|}
\hline Variable & $\begin{array}{c}\text { Men } \\
(n=141)\end{array}$ & $\begin{array}{l}\text { Women } \\
(n=159)\end{array}$ & $P$-value \\
\hline Mean score on nutritional habits ${ }^{a}$ & 61.8 & 66.7 & 0.003 \\
\hline Mean score on knowledge of healthy food & 56.8 & 57.9 & 0.627 \\
\hline Mean no. of alcohol units consumed/week & 4.01 & 2.46 & 0.002 \\
\hline $\begin{array}{l}\text { Of students exercising regularly } \\
\qquad>2 \mathrm{~h} / \text { week) }(\%)\end{array}$ & 58.1 & 41.9 & $<0.0001$ \\
\hline Of overweight/obese students (\%) & 58.8 & 41.2 & 0.066 \\
\hline Of students smoking cigarettes (\%) & 49.5 & 50.5 & 0.615 \\
\hline Of students drinking alcohol (\%) & 50.0 & 50.0 & 0.094 \\
\hline
\end{tabular}

amaximum score 100.

المجلة الصحية لشرق المتو سط، منظمة الصحة العالمية، المجلد الخامس عشر، العدد ؟، 9 +. 


\begin{tabular}{lccc}
\hline Table 3 Students' nutritional and health habits by faculty of study \\
\hline Variable & $\begin{array}{c}\text { Medical } \\
\text { faculty } \\
(\boldsymbol{n}=\mathbf{1 3 6})\end{array}$ & $\begin{array}{c}\text { Other } \\
\text { faculties }\end{array}$ & P-value \\
$(\boldsymbol{n}=\mathbf{1 6 4 )}$ & \\
\hline Mean score on knowledge of healthy food & 63.1 & 52.6 & $<0.0001$ \\
Mean no. of alcohol units consumed/week & 2.22 & 3.98 & $<0.0001$ \\
Of students smoking cigarettes (\%) & 35.2 & 64.8 & 0.020 \\
Of students drinking alcohol (\%) & 42.2 & 57.8 & 0.091 \\
\hline a & & &
\end{tabular}

\section{Discussion}

Before considering the implications of our findings, several limitations in the data must be acknowledged. This sample of university students is not representative of the whole population and therefore caution in generalization of the results is necessary. University students are younger and better educated than the whole population, and lifestyle behaviours in terms of smoking, drinking alcohol, eating poorly and being physically inactive do not show an effect on health in a short time perspective. Another limitation of the present study could be that health was measured only by self-reporting. It may be that participants did not report accurately or that a particular group of participants experienced more pressure to answer questions in a socially desirable manner. However, there are studies that show quite high correlations between reported and measured health variables, such as weight [11]. Despite these limitations, this study provides an extension of previous research on university students' health in Greece.

The overall mean score for both nutrition knowledge and healthy diet was medium. "Healthy" behaviours, such as avoiding fatty and high cholesterol foods and efforts to eat more fruits and fibre were often reported by the students. However, the prevalence of smoking $(49.5 \%$ for men and $50.5 \%$ for women) is one of the high- est reported in the literature for students. Similar studies worldwide have reported a prevalence of smoking among university students ranging from $23.4 \%$ to $44.0 \%$ for males and from $19.0 \%$ to $46.0 \%$ for females [3]. On the other hand, the percentage of students in our sample not consuming alcohol on a regular basis $(50.0 \%)$ is one of the highest reported in Europe [12]. Only a few individuals in our sample reported consuming excessive amounts on a weekly basis (>100 g for men and $>60 \mathrm{~g}$ for women.). This is consistent with the observation that the incidence of alcoholism in Greece, like other Mediterranean countries, is relatively low $[13,14]$.

Women students, although they exercised less regularly than men, were characterized by a greater effort to achieve healthy nutrition, a higher engagement in low-fat diet and a lower frequency of alcohol consumption. In addition, women had a lower rate of overweight/obesity which is likely to be related to more healthy nutrition. These gender differences have been reported by others as well $[15,16]$. It appears that either men are less susceptible to societal pressure to be thin or that there exists a reporting bias in which men are less likely to admit vulnerability to such pressures.

Although medical students had better knowledge about healthy food than others, there was no difference concerning their 
eating habits. On the other hand, some health hazards were also identified as less specific for medical students. A lower percentage of medical students reported smoking cigarettes and drinking alcohol than other students, probably because of their better knowledge of preventive behaviour and better health practices. We believe that physicians and medical students should not only have better knowledge and awareness of nutrition recommendations and practice guidelines relating to cardiovascular and other chronic disease risk reduction, but also set an example for their patients. Yet several studies have reported high tobacco and alcohol consumption among medical students $[17,18]$. Compared with these studies, the prevalence of smoking among
Greek medical students in Aristotle University $(35.2 \%)$ is among the highest in the world reported in the literature for medical students, even higher than that reported by Mammas et al. [6].

From the health educator's perspective, universities and colleges represent the final opportunity for the health and nutritional education of a large number of students. Our study adds information on students' lifestyle in Greece in comparison with other countries. Following WHO proposals for a European network of health-promoting universities [19], a detailed knowledge of lifestyles and health needs in students is essential and may help to plan more effective interventions in this setting.

\section{References}

1. Eyre H, Kahn R, Robertson RM. Preventing cancer, cardiovascular disease, and diabetes: a common agenda for the American Cancer Society, the American Diabetes Association, and the American Heart Association. Circulation, 2004, 109:3244-55.

2. The European health report 2002. Copenhagen, World Health Organization Regional Office for Europe, 2005 (European Series, No. 97).

3. Steptoe A et al. Trends in smoking, diet, physical exercise, and attitudes toward health in European university students from 13 countries, 1990-2000. Preventive medicine, 2002, 35:97-104.

4. Willet WC. Diet and health: what should we eat? Science, 1994, 264:532-7.

5. Trichopoulou A et al. Diet and overall survival in elderly people. British Medical journal, 1995, 311:1457-60.

6. Mammas I et al. Cigarette smoking, alcohol consumption, and serum lipid pro- file among medical students in Greece. European journal of public health, 2003, 13:278-82.

7. Mammas I et al. Nutrient intake and food consumption among medical students in Greece assessed during a Clinical Nutrition course. International journal of food sciences and nutrition, 2004, 55(1):1726.

8. Bertsias $\mathrm{G}$ et al. Fruit and vegetables consumption in relation to health and diet of medical students in Crete, Greece. International journal for vitamin and nutrition research, 2005, 75(2):107-17.

9. Stefanik PA, Trulson MF. Determining the frequency intakes of foods in large group studies. American journal of clinical nutrition, 1962, 11:335-43.

10. Obesity: preventing and managing the global epidemic. Report of a WHO consultation. Geneva, World Health Organization, 2000 (WHO Technical Report Series, No. 894). 
11. Stunkard AJ, Albaum JM. The accuracy of self-reported weights. American journal of clinical nutrition, 1981, 34:1593-9.

12. Smart RG, Ogborne A. Drinking and heavy drinking by students in 18 countries. Drug and alcohol dependence, 2000, 60(3):315-8.

13. Liakos A, Madianos M, Stefanis C. Alcohol consumption and rates of alcoholism in Greece. Drug and alcohol dependance, 1980, 6:425-30.

14. Bloomfield $\mathrm{K}$ et al. International comparisons of alcohol consumption. Alcohol research and health, 2003, 27(1):95-109.

15. Stock C, Wille L, Kramer A. Gender-specific health behaviors of German university students predict the interest in campus health promotion. Health promotion international, 2001, 16(2):145-54.
16. Monneuse MO, Bellisle F, Koppert G. Eating habits, food and health related attitudes and beliefs reported by French students. European journal of clinical nutrition, 1997, 51(1):46-53.

17. Richmond R. Teaching medical students about tobacco. Thorax, 1999, 54:70-80.

18. Dekker HM et al. Prevalence of smoking in physicians and medical students. and the generation effect in the Netherlands. Social science and medicine, 1993, 36(6):817-22.

19. Tsouros A et al., eds. Health promoting universities: concept, experience and framework for action. Copenhagen, World Health Organization Regional Office for Europe, 1998.

Preventing leading causes of premature death, disease and disability

Many of today's and tomorrow's leading causes of death, disease and disability (cardiovascular disease, cancer, chronic lung diseases, depression, violence, substance abuse, injuries, nutritional deficiencies, HIV/AIDS/STI and helminth infections) can be significantly reduced by preventing 6 interrelated categories of behaviour, that are initiated during youth and fostered by social and political policies and conditions. These are: tobacco use; behaviour that results in injury and violence; alcohol and substance use; dietary and hygienic practices that cause disease; sedentary lifestyle; and sexual behaviour that causes unintended pregnancy and disease.

Source: WHO School and youth health website (http://www.who.int/school_youth_health/en/) 